\title{
Stabilność oksydacyjna a skażenie mikrobiologiczne paliw
}

\begin{abstract}
Przedstawiono wyniki badania stabilności oksydacyjnej paliw o różnym udziale objętościowym FAME: $7 \%(V / V)$, $30 \%(V / V)$ oraz $100 \%(V / V)$. Badania prowadzono dla paliw kontaktowanych ze szczepionką oraz paliw sterylnych po upływie 10 i 40 dni przechowywania próbek. W 10-dniowym teście stosowano dwa rodzaje szczepionek. Wyniki badań wskazują na brak wpływu skażenia mikrobiologicznego paliw na ich stabilność oksydacyjną.

Słowa kluczowe: stabilność oksydacyjna, paliwa zawierające FAME, skażenie mikrobiologiczne.

\section{Oxidation stability and microbial contamination of fuels}

The paper presents the results of the oxidative stability of fuels with different volume fraction of FAME: $7 \%(\mathrm{~V} / \mathrm{V})$, $30 \%(V / V)$ and 100\% $(V / V)$. The study was conducted usinginnoculated fuels and sterile fuels after 10 and 40 days of samples storage. In the 10-day test, two types of innoculum were used. The results show no effect of microbial contamination of fuels on their oxidative stability.
\end{abstract}

Key words: oxidative stability, fuels containing FAME, microbial contamination.

\section{Wstęp}

Stosowanie biokomponentów w paliwach ciekłych jest wymagane dyrektywą Parlamentu Europejskiego i Rady 2009/28/WE z dnia 23 kwietnia 2009 r. w sprawie promowania stosowania energii ze źródeł odnawialnych. Użycie biokomponentów wiąże się jednak z wieloma problemami. Analiza wyników monitoringu paliw ciekłych pozwala stwierdzić, że najczęściej spotykanym odstępstwem od wymagań dla oleju napędowego z udziałem FAME jest stabilność oksydacyjna.

Istnieje wiele czynników, które wpływają na stabilność FAME [3, 10]. Dane literaturowe wskazują, że estry kwasów tłuszczowych są bardzo wrażliwe m.in. na działanie światła, temperaturę, obecność jonów metali, procesy utleniania oraz mają silniejsze działanie korodujące niż olej napędowy pochodzenia naftowego. Degradacja FAME pociąga za sobą zmiany w jego składzie i właściwościach.

Na stabilność FAME wpływają m.in. następujące czynniki:

- temperatura, intensywność światła, obecność naturalnych antyoksydantów, stopień nienasycenia cząsteczki, obecność metali, tlenu - które powodują procesy utleniania;

- długotrwałe przechowywanie (obecność struktur niena- syconych zwiększa reaktywność FAME). Niektórzy autorzy wskazują, że FAME po sześciomiesięcznym okresie przechowywania nie może być stosowane jako paliwo z uwagi na utratę stabilności;

- rozkład termiczny. Analiza TGA wykazała, że degradacja FAME widoczna jest już w $130^{\circ} \mathrm{C}$ w zależności od składu chemicznego i struktury cząsteczki. Paliwa węglowodorowe są bardziej odporne na działanie temperatury;

- zanieczyszczenie metalami, szczególnie miedzią (obecność tlenu w strukturze FAME zwiększa jego reaktywność w stosunku do metali). Rezultatem jest tworzenie nierozpuszczalnych osadów, żywic oraz produktów korozji;

- absorpcja wody (zwiększa podatność na rozkład mikrobiologiczny). Obecność wody w FAME powoduje zwiększoną degradację w wyniku hydrolizy, ale ten czynnik ma mniejsze znaczenie;

- wzrost mikroorganizmów. FAME jest biologicznie bardziej reaktywne ze względu na obecność łańcuchów węglowodorowych oraz dwóch atomów tlenu w cząsteczce. Enzymy wytwarzane przez bakterie atakują strukturę 
FAME i powodują jego degradację do kwasu octowego i kwasów tłuszczowych, które rozkładane są do ditlenku węgla i wody przez enzymy w ciągu reakcji. Mikroorganizmy mają potencjalny wpływ na procesy degradacji, następującej szybciej w przypadku FAME niż paliw węglowodorowych (zawierają one węglowodory aromatyczne oraz cykliczne węglowodory alifatyczne, które nie są dobrą pożywką dla mikroorganizmów) $[1,2,5,6,7,11]$. Higroskopijność FAME zwiększa podatność na rozkład mikrobiologiczny.

\section{Materiały}

Do komponowania paliw badawczych stosowano bazowy olej napędowy oraz bazowe FAME. Badania prowadzono na próbkach oleju napędowego B7, B30 i B100, zawierającego FAME w stężeniach odpowiednio: $7 \%(V / V)$,
$30 \%(V / V)$ oraz $100 \%(V / V)$. W charakterze szczepionki wykorzystano mieszaninę mikroorganizmów tlenowych wyizolowanych z próbek paliw pobranych ze zbiorników przemysłowych.

\section{Metodyka badań}

Zawartość mikroorganizmów w paliwach oznaczano metodą IP 395 Determination of viable aerobic microbial content of fuels and fuel components boiling below $390^{\circ} \mathrm{C}-$ Filtration and culture method. Zawartość mikroorganizmów w szczepionkach oznaczano według PN-EN ISO 8199:2010.

Do oceny stabilności mieszanek paliwowych wykorzystywano metodę PN-EN 15751 Paliwa do pojazdów samochodowych - Estry metylowe kwasów thuszczowych (FAME) jako samoistne paliwo i ich mieszaniny z olejem napędowym - Oznaczanie stabilności oksydacyjnej metoda przyspieszonego utleniania. Wymieniona metoda oznaczania stabilności opiera się na procesie absorbcji w wodzie lotnych produktów utleniania paliwa oraz pomiarze jej przewodności właściwej. Czas potrzebny do uzyskania gwałtownego wzrostu przewodności właściwej jest miarą odporności próbki paliwa na utlenianie $[4,8,9]$.

Ponadto do oceny stabilności paliw stosowano metodę PN-EN 16091 Ciekle przetwory naftowe - Paliwa i mieszaniny ze średnich destylatów naftowych i estrów metylowych kwasów tluszczowych (FAME) - Oznaczanie stabilności oksydacyjnej metoda szybkiego utleniania w matej skali. Zasada metody badawczej PN-EN 16091 opiera się na pomiarze zmian ciśnienia $\mathrm{w}$ szczelnie zamkniętym naczyniu testowym. Wynikiem badania jest czas, jaki upłynął od początku testu, tj. od momentu osiągnięcia przez próbkę temperatury $140^{\circ} \mathrm{C}$ do chwili spadku ciśnienia wewnątrz naczynia testowego o $10 \%[4,8,9]$.

\section{Wyniki badań}

Badania miały charakter porównawczy: prowadzono je na próbkach paliw skażonych oraz paliw sterylnych.

W celu skażenia paliw badawczych stosowano szczepionki (A1 i A2) będące wodną zawiesiną mikroorganizmów tlenowych wyizolowanych z próbek paliw pobranych ze zbiorników przemysłowych. Skład szczepionek podano w tablicy 1.

Tablica 1. Skład ilościowy szczepionek stosowanych w badaniach

\begin{tabular}{|c|c|c|c|}
\cline { 2 - 4 } \multicolumn{1}{c|}{} & \multicolumn{3}{c|}{ Zawartość mikroorganizmów [kom./ml] } \\
\cline { 2 - 4 } & $\begin{array}{c}\text { bakterie } \\
\text { tlenowe }\end{array}$ & drożdże & $\begin{array}{c}\text { grzyby } \\
\text { pleśniowe }\end{array}$ \\
\hline Szczepionka A1 & $2,4 \times 10^{6}$ & $2,0 \times 10^{6}$ & poniżej 10 \\
\hline Szczepionka A2 & $3,3 \times 10^{6}$ & poniżej 10 & $9,0 \times 10^{2}$ \\
\hline
\end{tabular}

Zgodnie z przyjętymi założeniami do próbek paliw (400 ml) oznaczonych kodami B7, B30 i B100 wprowadzano szczepionkę A1 lub A2 (1 ml), wstrząsano i odstawiano.
Analogicznie do próbek odniesienia (oznaczonych kodami B7RS, B30RS i B100RS) wprowadzano sterylny roztwór soli fizjologicznej. Próbki przechowywano w temperaturze $25^{\circ} \mathrm{C}$ w zaciemnionym miejscu.

Badania prowadzono w dwóch kierunkach: porównania stabilności oksydacyjnej próbek skażonych różnymi szczepionkami (A1 i A2) oraz badania stabilności próbek przechowywanych w dłuższym okresie (10 i 40 dni).

Wyniki badań zawartości mikroorganizmów dla próbek kontaktowanych ze szczepionką A1 oraz próbek sterylnych przedstawiono w tablicy 2.

Wyniki badań zawartości mikroorganizmów dla próbek kontaktowanych ze szczepionką A2 oraz próbek sterylnych przedstawiono $\mathrm{w}$ tablicy 3 .

W próbkach paliw kontaktowanych ze szczepionkami A1 i A2 stwierdzono obecność mikroorganizmów, przy czym ich zawartość była wyższa w próbkach o wyższej zawartości FAME. Ponadto w miarę wzrostu udziału FAME zmieniała się struktura skażenia, tj. obserwowano zdecydowany 
Tablica 2. Wyniki badań mikrobiologicznych po upływie 10 dni dla próbek skażonych szczepionką A1 oraz próbek sterylnych

\begin{tabular}{|c|c|c|c|}
\hline \multirow{2}{*}{$\begin{array}{c}\text { Kod } \\
\text { próbki }\end{array}$} & \multirow{2}{*}{$\begin{array}{c}\text { Kod } \\
\text { szczepionki }\end{array}$} & \multicolumn{2}{|c|}{$\begin{array}{r}\text { Zawartość mikroorganizmów } \\
{[\mathrm{kom} . / 1]}\end{array}$} \\
\cline { 3 - 4 } & & bakterie tlenowe & drożdże \\
\hline B7 & A1 & 4700 & 5200 \\
\hline B7RS & - & poniżej 100 & poniżej 100 \\
\hline B30 & A1 & 8200 & 8400 \\
\hline B30RS & - & poniżej 100 & poniżej 100 \\
\hline B100 & A1 & 5900 & 28000 \\
\hline B100RS & - & poniżej 100 & poniżej 100 \\
\hline
\end{tabular}

Tablica 3. Wyniki badań mikrobiologicznych po upływie 10 dni dla próbek skażonych szczepionką A2 oraz próbek sterylnych

\begin{tabular}{|c|c|c|c|}
\hline \multirow{2}{*}{$\begin{array}{c}\text { Kod } \\
\text { próbki }\end{array}$} & \multirow{2}{*}{$\begin{array}{c}\text { Kod } \\
\text { szczepionki }\end{array}$} & \multicolumn{2}{|c|}{$\begin{array}{r}\text { Zawartość mikroorganizmów } \\
{[\mathrm{kom} . / 1]}\end{array}$} \\
\cline { 3 - 4 } & & bakterie tlenowe & grzyby \\
\hline B7 & A2 & 1800 & poniżej 100 \\
\hline B7RS & - & poniżej 100 & poniżej 100 \\
\hline B30 & A2 & 6800 & 860 \\
\hline B30RS & - & poniżej 100 & poniżej 100 \\
\hline B100 & A2 & 20000 & 25000 \\
\hline B100RS & - & poniżej 100 & poniżej 100 \\
\hline
\end{tabular}

wzrost komórek drożdży i grzybów pleśniowych. Próbki kontaktowane z roztworem soli fizjologicznej pozostały sterylne. Równocześnie $\mathrm{z}$ badaniami mikrobiologicznymi prowadzono badania stabilności oksydacyjnej metodami PN-EN 15751 oraz PN-EN 16091 dla paliw skażonych oraz sterylnych.

W tablicy 4 przedstawiono wyniki badań stabilności oksydacyjnej paliw skażonych szczepionką A1 oraz odpowiadających im paliw sterylnych.

Wyniki badań stabilności oksydacyjnej dla próbek kontaktowanych ze szczepionką A2 oraz odpowiadających im

Tablica 4. Wyniki badań stabilności oksydacyjnej po 10 dniach przechowywania próbek skażonych szczepionką A1 oraz próbek sterylnych

\begin{tabular}{|c|c|c|}
\hline \multirow{2}{*}{ Paliwo } & \multicolumn{2}{|c|}{ Stabilność oksydacyjna (wynik z niepewnością) } \\
\cline { 2 - 3 } & wg PN-EN 15751 [h] & wg PN-EN 16091 [min] \\
\hline B7 & $31,2 \pm 4,5$ & $81 \pm 5$ \\
\hline B7RS & $32,4 \pm 4,7$ & $86 \pm 5$ \\
\hline B30 & $14,7 \pm 2,3$ & $48 \pm 3$ \\
\hline B30RS & $14,4 \pm 2,2$ & $51 \pm 3$ \\
\hline B100 & $7,2 \pm 1,2$ & $25 \pm 2$ \\
\hline B100RS & $7,4 \pm 1,3$ & $25 \pm 2$ \\
\hline
\end{tabular}

Tablica 5. Wyniki badań stabilności oksydacyjnej po 10 dniach przechowywania próbek skażonych szczepionką A2 oraz próbek sterylnych

\begin{tabular}{|c|c|c|}
\hline \multirow{2}{*}{ Paliwo } & \multicolumn{2}{|c|}{ Stabilność oksydacyjna (wynik z niepewnością) } \\
\cline { 2 - 3 } & wg PN-EN 15751 [h] & wg PN-EN 16091 [min] \\
\hline B7 & $37,2 \pm 5,3$ & $63 \pm 4$ \\
\hline B7RS & $32,4 \pm 4,7$ & $66 \pm 4$ \\
\hline B30 & $16,2 \pm 2,5$ & $52 \pm 3$ \\
\hline B30RS & $15,9 \pm 2,4$ & $49 \pm 3$ \\
\hline B100 & $7,5 \pm 1,3$ & $24 \pm 2$ \\
\hline B100RS & $7,7 \pm 1,3$ & $26 \pm 2$ \\
\hline
\end{tabular}

próbek sterylnych po 10-dniowym okresie przechowywania zaprezentowano w tablicy 5.

W wyniku przeprowadzonych badań stwierdzono, że stabilność oksydacyjna paliw skażonych szczepionką A2 oraz odpowiadających im paliw sterylnych o tej samej zawartości FAME kształtuje się na zbliżonym poziomie.

Test próbek B7, B30 i B100 skażonych szczepionką A2 oraz odpowiadających im próbek sterylnych B7RS, B30RS i B100RS przedłużono do 40 dni. Wyniki badań mikrobiologicznych po tym czasie zawiera tablica 6 .

W miarę wydłużania okresu przechowywania próbek

Tablica 6. Wyniki badań mikrobiologicznych dla próbek paliw kontaktowanych ze szczepionką A2 oraz paliw sterylnych po upływie $40 \mathrm{dni}$

\begin{tabular}{|c|c|c|c|}
\hline \multirow{2}{*}{$\begin{array}{c}\text { Kod } \\
\text { próbki }\end{array}$} & $\begin{array}{c}\text { Kod } \\
\text { szczepionki }\end{array}$ & \multicolumn{2}{|c|}{$\begin{array}{r}\text { Zawartość mikroorganizmów } \\
{[\text { kom./l] }}\end{array}$} \\
\cline { 3 - 4 } & & bakterie tlenowe & grzyby \\
\hline B7 & A2 & 2470 & poniżej 100 \\
\hline B7RS & - & poniżej 100 & poniżej 100 \\
\hline B30 & A2 & 8100 & 4400 \\
\hline B30RS & - & poniżej 100 & poniżej 100 \\
\hline B100 & A2 & poniżej 100 & 20000 \\
\hline B100RS & - & poniżej 100 & poniżej 100 \\
\hline
\end{tabular}

Tablica 7. Wyniki badań stabilności oksydacyjnej po 40 dniach przechowywania próbek skażonych szczepionką A2 oraz próbek sterylnych

\begin{tabular}{|c|c|c|}
\hline \multirow{2}{*}{ Paliwo } & \multicolumn{2}{|c|}{ Stabilność oksydacyjna (wynik z niepewnością) } \\
\cline { 2 - 3 } & wg PN-EN 15751 [h] & wg PN-EN 16091 [min] \\
\hline B7 & $29,9 \pm 4,4$ & $64 \pm 4$ \\
\hline B7RS & $34,2 \pm 4,9$ & $68 \pm 5$ \\
\hline B30 & $14,2 \pm 2,2$ & $43 \pm 3$ \\
\hline B30RS & $14,8 \pm 2,3$ & $46 \pm 3$ \\
\hline B100 & $5,5 \pm 1,0$ & $18 \pm 1$ \\
\hline B100RS & $6,0 \pm 1,1$ & $18 \pm 1$ \\
\hline
\end{tabular}


skażonych zaobserwowano wzrost sumarycznej zawartości mikroorganizmów w paliwach B7 i B30, natomiast w paliwie B100 stwierdzono zanik bakterii tlenowych i niewielki spadek zawartości grzybów pleśniowych.
Wyniki badania stabilności oksydacyjnej paliw B7, B30 i B100 kontaktowanych ze szczepionką A2 oraz paliw sterylnych B7RS, B30RS oraz B100RS po upływie 40 dni przechowywania zamieszczono w tablicy 7.

\section{Podsumowanie i wnioski}

W ramach realizowanego projektu przeprowadzono badania mające na celu określenie wpływu skażenia mikrobiologicznego paliw zawierających FAME na ich stabilność oksydacyjną. Badaniami objęto paliwa o różnych udziałach objętościowych FAME, wynoszących: 7\% $(V / V), 30 \%(V / V)$ i $100 \%(V / V)$. Analizę zawartości mikroorganizmów oraz stabilności oksydacyjnej z zastosowaniem aparatów Rancimat i PetroOxy wykonywano w założonych przedziałach czasowych: po upływie 10 dni (dla dwóch szczepionek) i 40 dni (dla jednej szczepionki) przechowywania paliw. Badania miały charakter porównawczy: prowadzono je na paliwach skażonych oraz sterylnych.
Zróżnicowany skład szczepionek stosowanych w badaniach wskazuje, że w warunkach wykonywanego testu żadna $\mathrm{z}$ grup mikroorganizmów tlenowych, nie powoduje degradacji paliwa skutkującej obniżeniem stabilności oksydacyjnej. Zarówno próbki paliw skażonych szczepionką A1, jak i szczepionką A2 wykazują stabilność oksydacyjną na takim samym poziomie jak odpowiadające im próbki sterylne.

Przeprowadzone badania świadczą o braku istotnego wpływu skażenia mikrobiologicznego na stabilność oksydacyjną paliw zawierających FAME. Różnice w stabilności oksydacyjnej paliw skażonych i sterylnych nie przekraczały wartości niepewności stosowanych metod badawczych.

Prosimy cytować jako: Nafta-Gaz 2016, nr 2, s. 108-111, DOI: 10.18668/NG.2016.02.05

Artykuł nadesłano do Redakcji 12.10.2015 r. Zatwierdzono do druku 24.12.2015 r.

Artykuł powstał na podstawie pracy statutowej pt. Wpływ skażenia mikrobiologicznego na stabilność termooksydacyjna oleju napędowego zawierającego FAME - praca INiG - PIB na zlecenie MNiSW, nr archiwalny: DK-4100-10/15.

\section{Literatura}

[1] Bucker F., Santestevan N. A., Roesch L. F., Jacques R. J. S., Peralba M. C. R., Camargo F. A. O., Bento F. M.: Impact of biodiesel on biodeterioration of stored Brazilian diesel oil. International Biodeterioration \& Biodegradation 2011, vol. 65, s. $172-178$.

[2] Chrzanowski Ł., Dziadas M., Ławniczak Ł., Cyplik P., Białas W., Szulc A., Lisiecki P., Jeleń H.: Biodegradation of rhamnolipids in liquid cultures: effect of biosurfactant dissipation on diesel fuel/B20 blend biodegradation efficiency and bacterial community composition. Bioresource Technology 2012, vol. 111, s. $328-335$.

[3] Jakeria M. R., Fazal M. A., Haseeb A. S. M. A.: Influence of different factors on the stability of biodiesel: A review. Renewable and Sustainable Energy Reviews 2014, vol. 30, s. 154-163.

[4] Molenda J., Świgoń K., Urzędowska W., Sacha D.: Korelacja wyników badań stabilności oksydacyjnej biopaliw silnikowych uzyskanych za pomoca testu Rancimat oraz Petrooxy. Nafta-Gaz 2010, nr 10, s. 922-926.

[5] Owsianiak M., Chrzanowski Ł., Szulc A., Staniewski J., Olszanowski A., Olejnik-Schmidt A. K., Heipieper H. J.: Biodegradation of diesel/biodiesel blends by a consortium of hydrocarbon

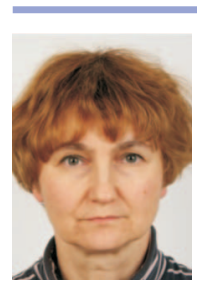

Mgr inż. Anna DUDA

Specjalista badawczo-techniczny w Zakładzie Paliw i Procesów Katalitycznych.

Instytut Nafty i Gazu - Państwowy Instytut Badawczy ul. Lubicz 25 A

31-503 Kraków

E-mail: anna.duda@inig.pl degraders: Effect of the type of blend and the addition of biosurfactants. Bioresource Technology 2009, vol. 100, s. 1497-1500.

[6] Pasqualino J. C., Montané D., Salvadó J.: Synergic effects of biodiesel in the biodegradability of fossil-derived fuels. Biomass and Bioenergy 2006, vol. 30, s. 874-879.

[7] Restrepo-Flórez J. M., Bassi A., Rehmann L., Thompson M. R.: Effect of biodiesel addition on microbial community structure in a simulated fuel storage system. Bioresource Technology 2013, vol. 147, s. 456-463.

[8] Sacha D.: Ocena stabilności oksydacyjnej paliw do silników o zapłonie samoczynnym wedtug projektowanych wymagań CEN. Nafta-Gaz 2013, nr 11, s. 858-867.

[9] Sacha D.: Wptyw FAME pochodzenia zwierzęcego na stabilność oksydacyjna olejów napędowych. Nafta-Gaz 2011, nr 9, s. 667-673.

[10] Schleicher T., Werkmeister R., Russ W., Meyer-Pittroff R.: Microbiological stability of biodiesel-diesel-mixtures. Bioresource Technology 2009, vol. 100, s. 724-730.

[11] Sørensen G., Pedersen D. V., Nørgaard A. K., Sørensen K. B., Nygaard S. D.: Microbial growth studies in biodiesel blends. Bioresource Technology 2011, vol. 102, s. 5259-5264.

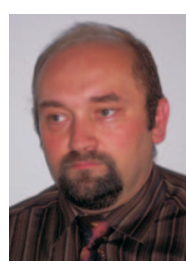

Mgr inż. Dariusz SACHA

Starszy specjalista badawczo-techniczny w Zakładzie Oceny Właściwości Eksploatacyjnych.

Instytut Nafty i Gazu - Państwowy Instytut Badawczy

ul. Lubicz 25 A

31-503 Kraków

E-mail: dariusz.sacha@inig.pl 